\title{
Seasonal Flow Reversals of Intermediate Waters in the Canary Current System East of the Canary Islands
}

\author{
FRANCISCO MACHÍN \\ Facultad de Ciencias del Mar, Universidad de Las Palmas de Gran Canaria, Las Palmas, Spain \\ JoSEP L. PELEGRÍ \\ Institut de Ciències del Mar, CSIC, Barcelona, Spain \\ E. Fraile-Nuez, P. VÉLEZ-Belchí, And F. LóPEZ-LAAtZen \\ Centro Oceanográfico de Canarias, Instituto Español de Oceanografía, Santa Cruz de Tenerife, Spain
}

A. HERnÁNDEZ-GuERrA

Facultad de Ciencias del Mar, Universidad de Las Palmas de Gran Canaria, Las Palmas, Spain

(Manuscript received 22 July 2009, in final form 19 March 2010)

\begin{abstract}
Two 9-yr current-meter and salinity records, together with climatological data, reveal marked seasonal variability of the intermediate flow at a key location in the Canary Basin. The region is characterized by a summer (July-September) and early fall (October) northward progression of Antarctic Intermediate Water followed by a fall (November-December) intense flow reversal of Mediterranean Water. A Sverdrup-type model confirms that these movements are associated with stretching or shrinking of the intermediate water strata.
\end{abstract}

\section{Introduction}

Two water masses interleave in the Canary Basin at intermediate levels: northward-flowing Antarctic Intermediate Water (AAIW) and southward-flowing Mediterranean Water (MW). AAIW may be found in the 600-1100-m depth range, whereas MW reaches deeper, roughly from 900- to 1500-m depth (van Aken 2000; Machín and Pelegrí 2009). AAIW and MW are characterized by minimum $(S<35.3)$ and maximum $(S>35.5)$ salinity values, respectively (Arhan et al. 1994; Machín et al. 2006). Both MW and AAIW are particularly important in the thermohaline circulation because young MW is one of the factors that affects deep water formation through the salinity of the North Atlantic Ocean, whereas old AAIW represents part of the final path for deep

Corresponding author address: Francisco Machín, Facultad de Ciencias del Mar, Universidad de Las Palmas de Gran Canaria, Campus Universitario de Tafira, 35017 Las Palmas de Gran Canaria, Spain.

E-mail: fmachin@becarios.ulpgc.es waters to return to the surface ocean (Sloyan and Rintoul 2001; Saenko et al. 2003). These two globally important intermediate water masses are juxtaposed in the Canary Basin, with the potential for mixing between them.

In January 1997, five moorings were set in the Lanzarote passage, located between the Canary Islands and the African coast, to collect data from the eastern boundary current (EBC) of the North Atlantic subtropical gyre, also known as the Canary Current system (Parrilla et al. 2002; Knoll et al. 2002; Hernández-Guerra et al. 2003). This passage is the main path for the northward penetration of AAIW along the North Atlantic eastern margin (Machín and Pelegrí 2009). EBC-4, located in the middle of this channel, is the only mooring still active (Fig. 1). In this work, we will analyze nine years of current velocity and salinity data acquired on this mooring at nominal depths of 870 and $1230 \mathrm{~m}$. The relevance of these long current time series is that they can detect the slow mean motion of several water masses, located at different depth ranges, as well as their seasonal and interannual variability. 


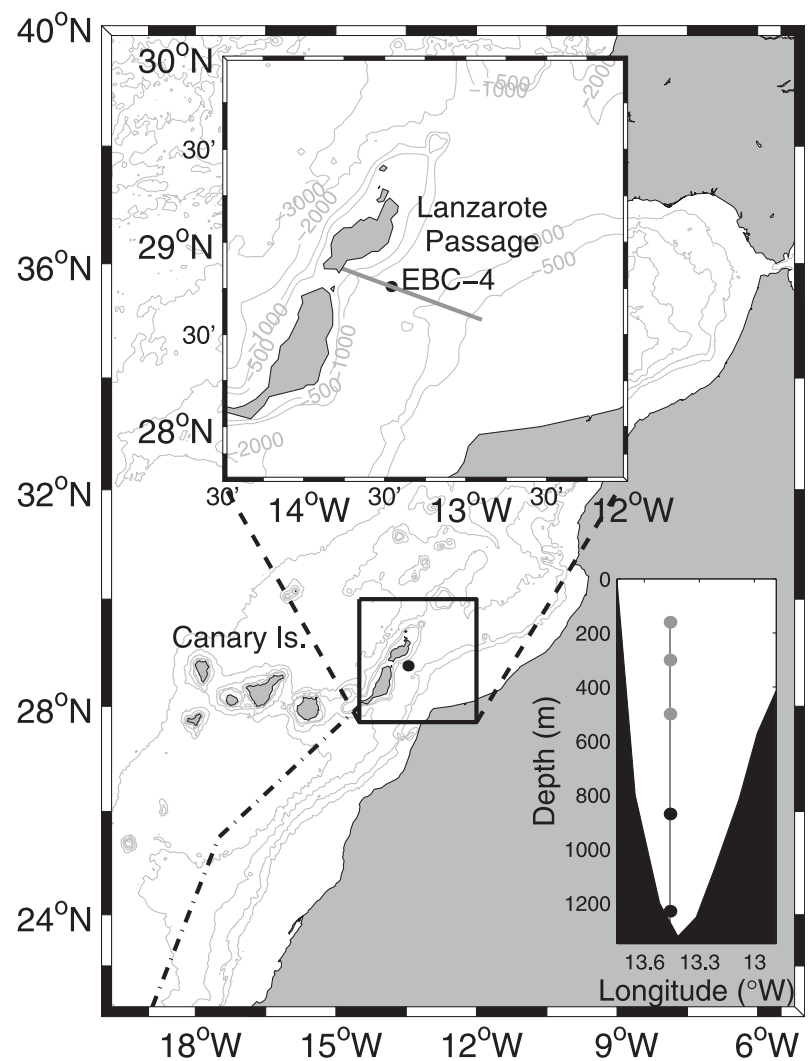

FIG. 1. Eastern boundary of the North Atlantic subtropical gyre. Dotted-dashed line in the western lower limit represents the west bound of the domain used for estimation of volume transports shown in Fig. 6. Upper inset shows the Lanzarote Passage with a gray line indicating the section used to produce the bathymetry in the lower inset, which shows the vertical distribution of current meters (those actually used are colored in black).

The aim of this note is to analyze the seasonal variability recorded by the EBC-4 mooring at intermediate depths and to investigate the mechanisms that explain this variability. Section 2 describes the dataset and what it tells us about the seasonal variability of intermediate waters, whereas section 3 introduces a simple model to explain the variability in the dynamics at intermediate levels. Section 4 sums up with the discussion and some conclusions.

\section{Long-term mooring data, time-lagged correlations, and climatological footprint}

Figure 2 shows the distribution of velocity observations at 870 and $1230 \mathrm{~m}$, which present a clear alignment of the velocity field with the passage's orientation. Hence, the velocities recorded by the EBC-4 mooring at intermediate levels are initially projected on the maximum variance axis $\left(38.8^{\circ}\right.$ at $870 \mathrm{~m}$ and $49.8^{\circ}$ at $\left.1230 \mathrm{~m}\right)$ to ensure that we use the along-channel velocity component. Next, the nine years of these daily-mean values are averaged to generate a canonical year of alongpassage velocities at both water depths (Figs. 3a,b). Hereafter, we will refer to northward or southward flows, but we actually mean the flow along the passage's axis.

At 870-m depth, a weak northward average velocity is observed from February to June, with a mean value of $0.9 \pm 1.0 \mathrm{~cm} \mathrm{~s}^{-1}$, which intensifies from July until October, reaching mean velocities of $3.0 \pm 1.3 \mathrm{~cm} \mathrm{~s}^{-1}$ (Table 1). In November, this flow rapidly reverses and heads south with similar intensity during two months, with a mean velocity of $-2.6 \pm 2.3 \mathrm{~cm} \mathrm{~s}^{-1}$. At $1230 \mathrm{~m}$, the velocity pattern is more variable than at $870 \mathrm{~m}$, with velocities of $-0.9 \pm 2.1$ and $-0.4 \pm 1.3 \mathrm{~cm} \mathrm{~s}^{-1}$ from February to June and from July to October, respectively. However, during November and December, the flow displays a better defined southward component of $-2.5 \pm 1.2 \mathrm{~cm} \mathrm{~s}^{-1}$, close to that recorded by the $870-\mathrm{m}$ current meter during the same period. This southward flow has been observed every fall in the whole record, with rather similar intensities and daily maximum values up to $-12 \mathrm{~cm} \mathrm{~s}^{-1}$.

We next explore the salinity signal in the current meters to investigate whether its variability is related to the seasonal variability of the velocity time series. With this goal, the salinity measured by the current meters is a posteriori corrected with salinity data from hydrographic measurements taken during the mooring maintenance operations (accuracy in salinity sensor is \pm 0.02 ). Figures $3 \mathrm{c}$, d present the year-averaged salinity at 870 and 1230-m depths, as well as several CTD salinity observations taken at these depths (CTD data were originally calibrated with bottle samples). At $870 \mathrm{~m}$, a relatively low salinity value is observed from February to July, $35.27 \pm 0.03$, which decreases further during September and October to $35.25 \pm 0.03$. This minimum salinity values correspond to the maximum northward extension of AAIW, which occurs some time after the maximum northward velocity (first half of September). In December and January, on the other hand, we find a remarkable salinity increase to $35.35 \pm 0.05$. This now occurs after the maximum southward flow (early December), indicating the appearance of MW. The data at $1230 \mathrm{~m}$ display a pattern similar to the data at $870 \mathrm{~m}$; however, the minimum average salinity value occurs at this depth only during September (35.27 \pm 0.03 ), after a period of about two months of nearly zero velocity. Salinity then increases to a December maximum average of $35.49 \pm 0.04$, less than one month after the maximum southward flow. Again, the salinity peak values suggest the presence of AAIW/MW of southern/ northern origin. 

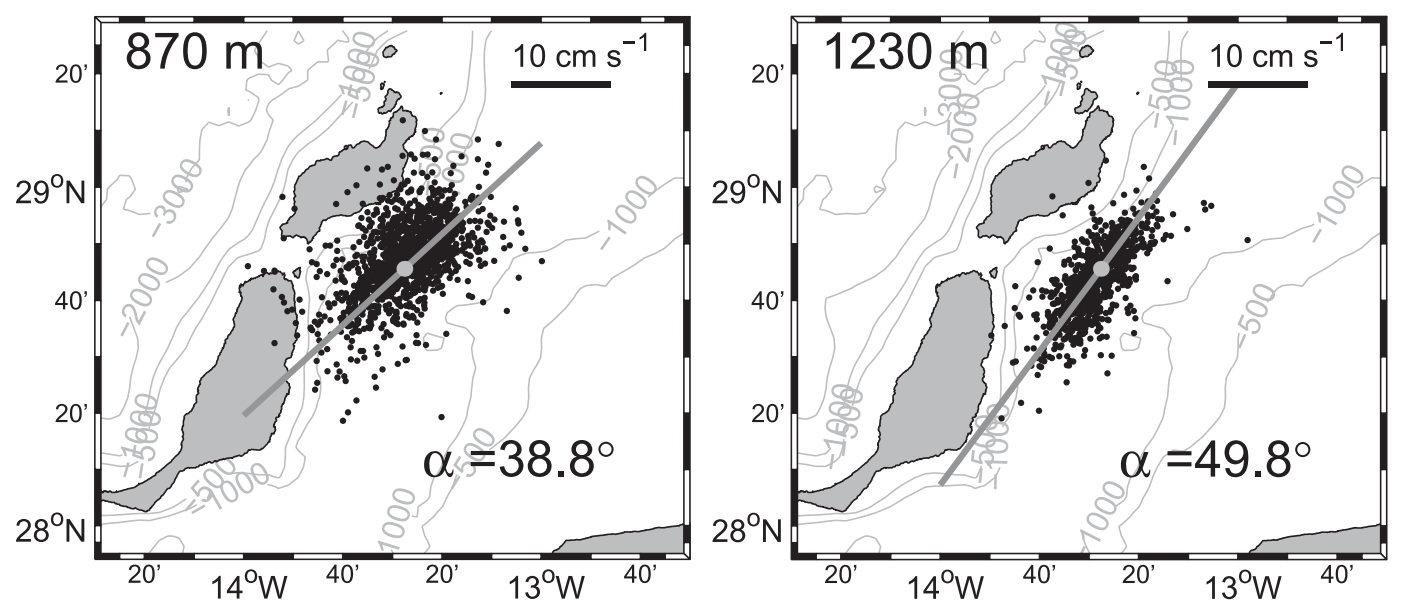

FIG. 2. Scatterplot of velocity observations at (left) 870 and (right) $1230 \mathrm{~m}$. The maximum variance direction and the corresponding angle are indicated. The large gray dot indicates the mooring position, which is also the origin of the scattered velocity vectors, and each individual dot represents the tip of these velocity vectors, their magnitude according to the enclosed velocity scale.

We quantify the response of the salinity to the velocity field by computing the lagged cross-correlations between both variables. The maximum lagged cross-correlation [i.e., the time between the maximum northward (southward) velocities and the minimum (maximum) salinity] reflects the cumulative effect of the meridional velocities on the meridional extension of AAIW (MW). Figures $4 \mathrm{a}, \mathrm{b}$ show the whole velocity and salinity time series at both depths, after applying a 5-day low-pass filter. Figures $4 \mathrm{c}, \mathrm{d}$ show the lagged cross-correlation (velocity leading salinity) for the whole time series as well as for three partial time series, showing only those correlation values significant above $95 \%$. Figure $4 \mathrm{c}$ shows the lagged cross-correlation using the whole time series, which shows maximum correlation lag times of 20-30 days at $1230 \mathrm{~m}$ and about 45 days at $870 \mathrm{~m}$. The correlation increases substantially when we use only the second half of the velocity time series (1 July-31 December), which corresponds to the period when we observe the maximum northward and southward velocities; in this case, both depths give maximum correlation lag times of about one month.

We further refine these calculations by producing two new velocity time series, with the first one including only the intense northward flow period at $870 \mathrm{~m}$ (1 July-30 October) and the second one including only the intense southward flow period at both depths (1 November31 December). The results show that the minimum salinity follows the northward flow by some 85-90 days, whereas the maximum salinity follows the southward flow by some 10-20 days (Fig. 4d). The different time lags are related to the cumulative effect of the meridional velocities in transporting either AAIW or MW. The period of northward AAIW is larger than for southward MW; this implies that the maximum northward extension of AAIW occurs substantially later than the maximum northward flow, whereas the southward (salty) MW displays a relatively small time lag. In a sense, AAIW has greater inertia than MW because it brings water from far equatorial regions while the short-term southward flow essentially moves water located north of the Canary Islands.

We have carried out a simple sensitivity test to check the soundness of the velocity-salinity time-lagged crosscorrelations, which consists of splitting the original time series into two time series of equal length, each $4 \frac{1}{1} 2$ years long. The results basically agree with those obtained from the original time series, in particular with respect to the lag times, whereas the differences are mainly related to the correlation coefficient values that are slightly higher or lower than the original ones.

Although the eastern North Atlantic is highly prone to the appearance of meddies (Siedler et al. 2005), EBC4 did not record a single meddy during the whole 9-yr series. It is likely that the relatively large horizontal scale of meddies, on the order of the Lanzarote Passage's width, and the year-mean northward flow through the passage make it difficult for meddies to flow southward through the passage.

To sum up, the salinity- and velocity-lagged correlations show consistent patterns of latitudinal displacement of intermediate waters, with northward (at $870 \mathrm{~m}$ ) or no (at $1230 \mathrm{~m}$ ) motion in summer followed by the presence of AAIW and southward motions in fall (at both depths) followed by the presence of MW. The most remarkable feature is this intense flow reversal over a water column 

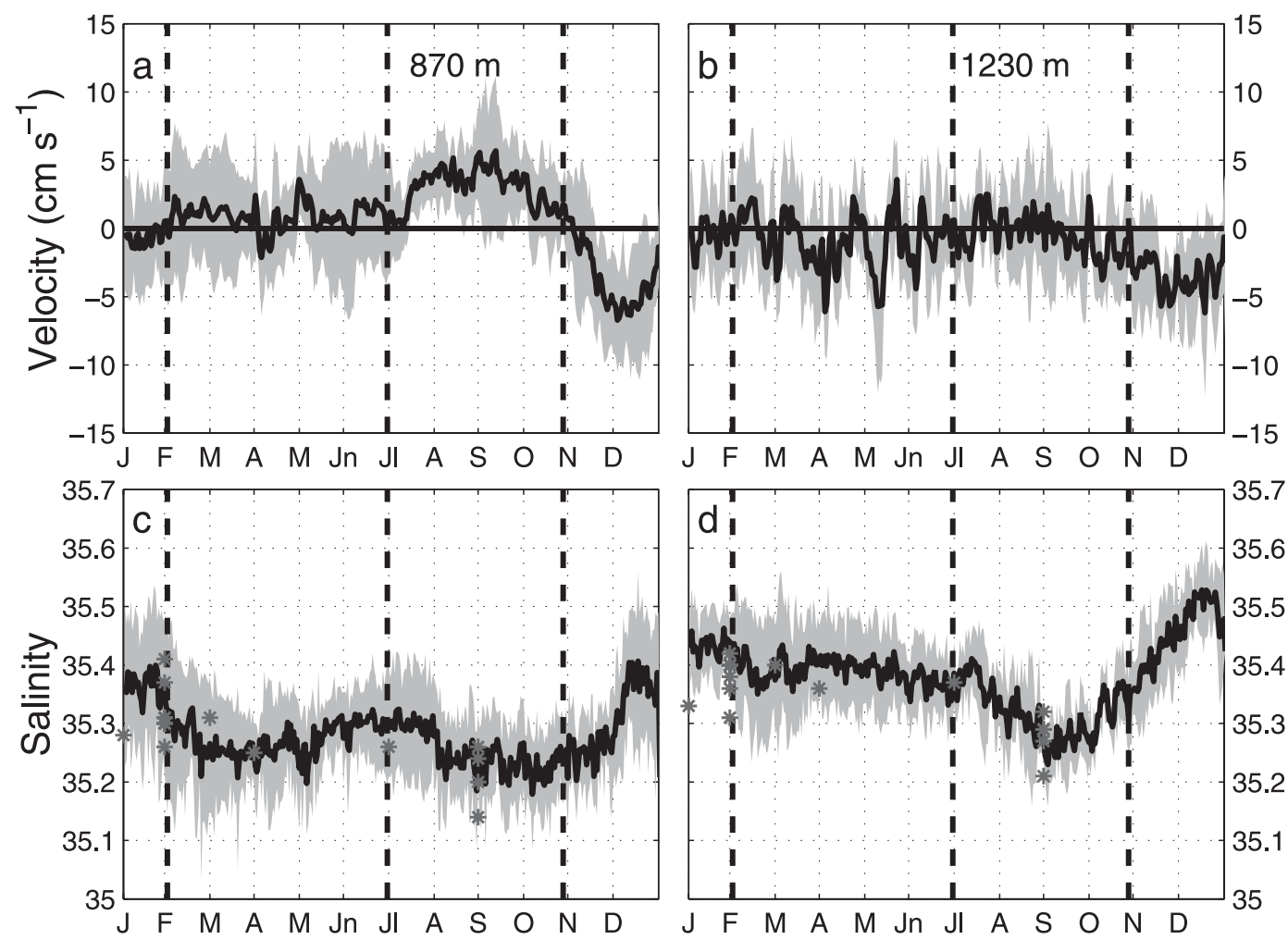

FIG. 3. Average velocity distribution along the maximum variance axis at (a) 870 and (b) $1230 \mathrm{~m}$. (c),(d) Average salinity distribution at the same depths. One standard deviation is shaded in gray. Dark gray stars represent observations from CTD casts at the current-meter actual depths. Vertical lines represent major transitions used for calculating lagged cross-correlations.

at least $350 \mathrm{~m}$ thick during fall, between about early September and early December, followed by a sharp maximum salinity peak in mid-December. Table 1 summarizes some of these numbers at both water depths.

The flow reversal is well defined in the mean currentmeter velocity and salinity observations, indicating a persistent seasonal pattern. Therefore, we may expect it should be visible in climatological datasets. Figure 5 presents the seasonal difference from climatology in salinity and oxygen concentration from summer to fall along the continental slope, as extracted from the World Ocean Atlas 2005 [in the climatological analysis, summer runs from July to September (JAS) and fall runs from October to December (OND)]. The climatology

TABLE 1. The 9-yr mean and standard deviations along-channel velocity $u$, across-channel velocity $v$, salinity, and cross-correlation lag times $\tau$ during relevant periods at 870 and $1230 \mathrm{~m}$. Minimum and maximum values for the relevant periods are also included.

\begin{tabular}{|c|c|c|c|c|c|c|c|}
\hline \multicolumn{8}{|c|}{$870 \mathrm{~m}$} \\
\hline & \multicolumn{2}{|c|}{$u\left(\mathrm{~cm} \mathrm{~s}^{-1}\right)$} & \multirow[t]{2}{*}{$\tau$ (days) } & \multicolumn{2}{|c|}{$v\left(\mathrm{~cm} \mathrm{~s}^{-1}\right)$} & \multicolumn{2}{|c|}{ Salinity } \\
\hline & Mean & $\operatorname{Min} / \max$ & & Mean & $\operatorname{Min} / \max$ & Mean & $\operatorname{Min} / \max$ \\
\hline February-June & $0.9 \pm 1.0$ & $-2.1 / 3.6$ & 24 & $0.6 \pm 0.5$ & $-1.4 / 2.8$ & $35.27 \pm 0.03$ & $35.20 / 35.33$ \\
\hline July-October & $3.0 \pm 1.3$ & $0.1 / 5.7$ & 84 & $0.8 \pm 0.6$ & $-1.1 / 3.0$ & $35.25 \pm 0.03$ & $35.18 / 35.32$ \\
\hline November-December & $-2.6 \pm 2.3$ & $-6.7 / 1.7$ & 7 & $0.8 \pm 0.9$ & $-1.3 / 3.2$ & $35.32 \pm 0.05$ & $35.20 / 35.41$ \\
\hline
\end{tabular}

$1230 \mathrm{~m}$

\begin{tabular}{|c|c|c|c|c|c|c|c|}
\hline & \multicolumn{2}{|c|}{$u\left(\mathrm{~cm} \mathrm{~s}^{-1}\right)$} & \multirow[t]{2}{*}{$\tau$ (days) } & \multicolumn{2}{|c|}{$v\left(\mathrm{~cm} \mathrm{~s}^{-1}\right)$} & \multicolumn{2}{|c|}{ Salinity } \\
\hline & Mean & $\operatorname{Min} / \max$ & & Mean & $\operatorname{Min} / \max$ & Mean & $\operatorname{Min} / \max$ \\
\hline February-June & $-0.9 \pm 2.1$ & $-6.1 / 3.6$ & 22 & $-0.1 \pm 1.1$ & $-2.1 / 2.2$ & $35.39 \pm 0.03$ & $35.33 / 35.43$ \\
\hline July-October & $-0.4 \pm 1.3$ & $-3.8 / 2.5$ & 87 & $-0.3 \pm 1.0$ & $-2.0 / 1.3$ & $35.32 \pm 0.03$ & $35.23 / 35.41$ \\
\hline November-December & $-2.5 \pm 1.2$ & $-6.2 / 1.2$ & 21 & $-0.1 \pm 0.7$ & $-1.7 / 2.1$ & $35.44 \pm 0.04$ & $35.35 / 35.53$ \\
\hline
\end{tabular}


(a)

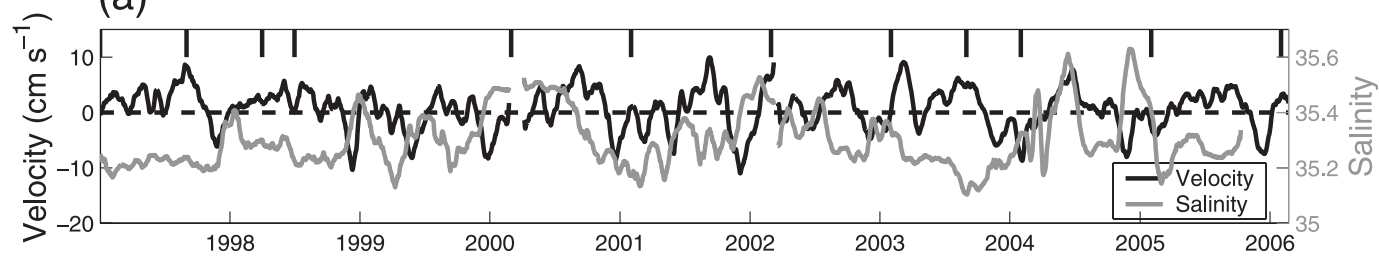

(b)
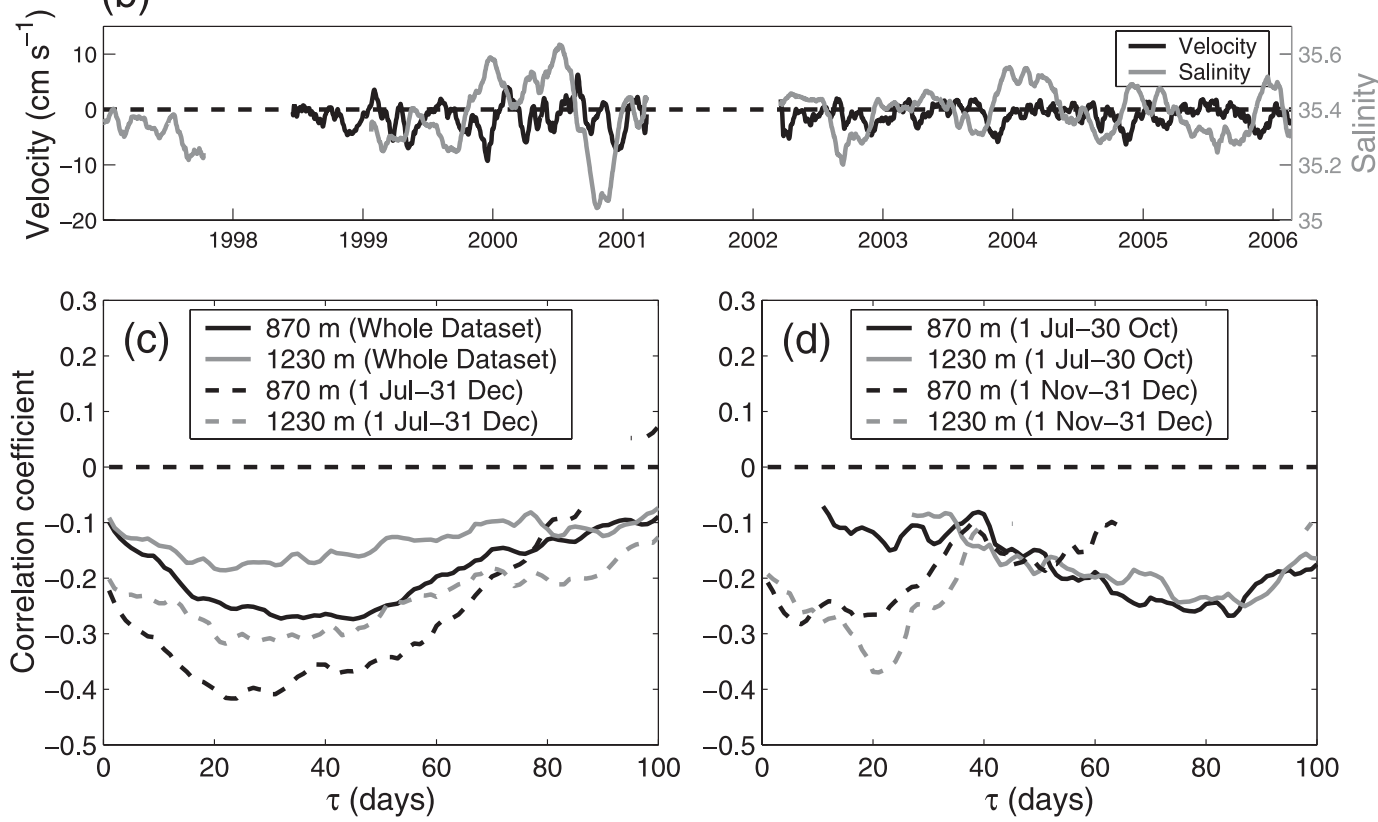

FIG. 4. Along-channel velocity and salinity time series at (a) 870- and (b) 1230-m depths. (c),(d) Time-lagged crosscorrelations between the velocity and salinity time series, showing only significant values above $95 \%$. In all cases, we use the full available salinity time series but limit the velocity time series as follows: (c) full period (solid lines) and 1 Jul-31 Dec (dashed lines) and (d) 1 Jul-30 Oct (solid lines) and 1 Nov-31 Dec (dashed lines).

shown in Fig. 5, built from the nodes linked on the map, is based on 5053 salinity observations in summer and 3448 in fall, whereas there are 1656 dissolved oxygen observations in summer and 2161 during fall. A notable increase in salinity is observed north of $28^{\circ} \mathrm{N}$ above $1500-\mathrm{m}$ depth, and is particularly sharp in the region occupied by the mooring array. The oxygen content also increases from summer to fall, though not as clearly as in the salinity field. Both the salinity and oxygen increases indicate that the MW contribution is higher during fall than summer because MW is marked by high salinity and oxygen and AAIW is lower in both (Castro et al. 1998; Pérez et al. 2001; Machín et al. 2006; Machín and Pelegrí 2009).

\section{Physical forcing}

Recent studies have shown that the dynamics at intermediate levels may be investigated using Sverdrup-type models (Schmid et al. 2000; Machín and Pelegrí 2009). Here, we further use a Sverdrup-type model, fed with climatological information, to evaluate volume fluxes in the Canary Current system, which is an eastern boundary current system. We start with the vorticity equation $\beta v=f(\partial w / \partial z)$, where $v$ and $w$ are the meridional and vertical velocity components, respectively; $f=2 \Omega \sin \theta$ is the Coriolis parameter; and $\beta=d f / d y$, where $\Omega$ is the earth's angular velocity, $\theta$ is the latitude, and $y$ is the northward horizontal axis. This equation may be vertically integrated over an isoneutral layer, comprising a given water stratum, with the lower isoneutral surface at $z=-h_{2}$ and the upper isoneutral at $z=-h_{1}$ (we use neutral density $\gamma^{n}$ throughout; Jackett and McDougall 1997). Assuming that there is no mixing between this and the adjacent layers, the meridional transport per unit length is

$$
\int_{-h_{2}}^{-h_{1}} v d z=-\frac{f}{\beta}\left(\frac{\partial H}{\partial t}+v \frac{\partial H}{\partial y}\right),
$$

where $H=h_{2}-h_{1}$ is the spatially variable thickness of the isoneutral layer. The first and second terms on the 

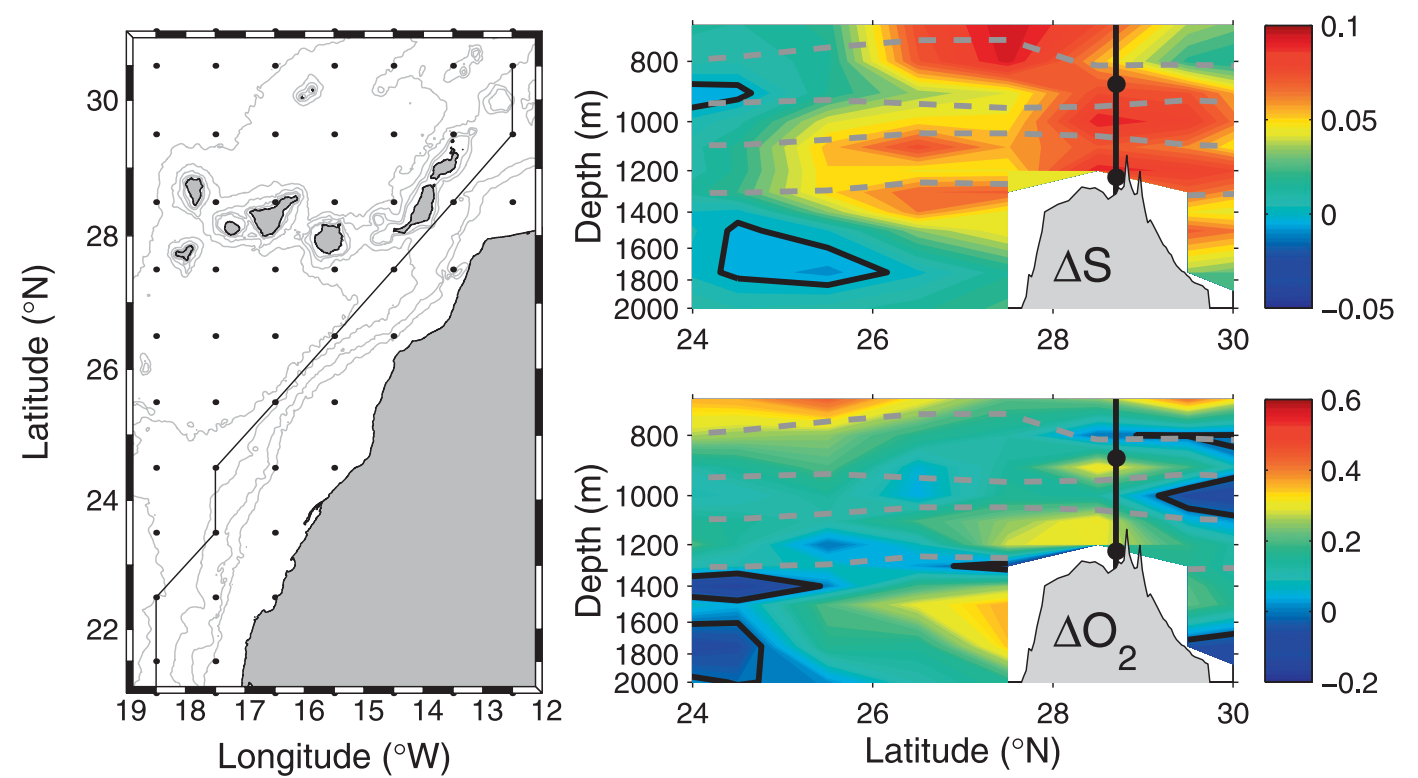

FIG. 5. Climatological salinity and dissolved oxygen $\left(\mathrm{mL} \mathrm{L}^{-1}\right)$ changes from summer (JAS) to fall (OND) along the African continental slope. (left) The map indicates the path used to build the section. (right) The vertical line represents the mooring, with the current meters at 870 and $1230 \mathrm{~m}$ shown as black dots. Gray dashed lines correspond to $27.5,27.6,27.7$, and $27.8 \mathrm{~kg} \mathrm{~m}^{-3}$ neutral densities averaged from summer and fall. Note the vertical logarithm depth scale.

right-hand side of (1) are the material derivative, written as the sum of the local temporal rate and the meridional advective terms, $d H / d t=\partial H / \partial t+v(\partial H / \partial y)$, assuming that the meridional term is much greater than the zonal one (Mittelstaedt 1981; Roemmich and Wunsch 1985; Iorga and Lozier 1999; Fratantoni and Richardson 1999).

From (1), assuming a depth-independent velocity within the isoneutral layer, we obtain an explicit expression for the velocity,

$$
v=-\frac{\frac{\partial H}{\partial t}}{\frac{\partial H}{\partial y}+\frac{\beta H}{f}} .
$$

We integrate this velocity over a zonal transect of length $100 \mathrm{~km}$ from the continental slope, which is the main propagating path for intermediate waters in the region (Machín and Pelegrí 2009), to estimate the total meridional transport $\left[V_{i} \equiv V\left(y_{i}\right)\right]$ of intermediate waters at a latitude $y=y_{i}$,

$$
V_{i}=\int_{L} \int_{-h_{2}}^{-h_{1}} v d z d x
$$

The horizontal distribution of these variables is evaluated using the seasonal hydrographic climatology (World Ocean Atlas 2005). We set isoneutrals $\gamma^{n}=27.3$ and
$27.6 \mathrm{~kg} \mathrm{~m}^{-3}$ as the upper and lower limits of the AAIW layer, whereas the MW layer runs from 27.6 to $27.8 \mathrm{~kg} \mathrm{~m}^{-3}$ (Machín and Pelegrí 2009). The top panel of Fig. 6 shows the zonally integrated meridional transport of intermediate waters (AAIW plus MW) during each season, from $24^{\circ} \mathrm{N}$ until the latitude where the current meters were moored. The seasonal variability modeled at the EBC-4 location $\left(28^{\circ} 43^{\prime} \mathrm{N}\right)$ shows a northward summer transport [2.0 Sv $\left(1 \mathrm{~Sv} \equiv 10^{6} \mathrm{~m}^{3} \mathrm{~s}^{-1}\right)$ ], which rapidly reverses to a fall southward flow $(4.9 \mathrm{~Sv})$. Southward winter $(3.3 \mathrm{~Sv})$ and spring $(2.7 \mathrm{~Sv})$ values lay between the fall and summer scenarios, a variability that fits qualitatively with previous observations in the region (Hernández-Guerra et al. 2005; Machín et al. 2006). The bottom panel of Fig. 6 shows the latitudinal distribution of the fall velocity estimated with expression (2) for both layers. This gives southward values near $2.4 \mathrm{~cm} \mathrm{~s}^{-1}$ at the mooring location for the AAIW layer and $3.6 \mathrm{~cm} \mathrm{~s}^{-1}$ for the MW layer, in fair agreement to average observed values during that season.

We may directly estimate volume transports from the current-meter data by considering the area below 600-m depth that surrounds the two deepest current meters. Assuming a U-shaped area (Fig. 1) this amounts to $30.1 \times 10^{6} \mathrm{~m}^{2}$. Hence, maximum southward velocities of $5-10 \mathrm{~cm} \mathrm{~s}^{-1}$ correspond to a southward volume transport of 1.5-3.0 Sv, an outcome that fits reasonably well with the southward volume transports obtained from the model. 

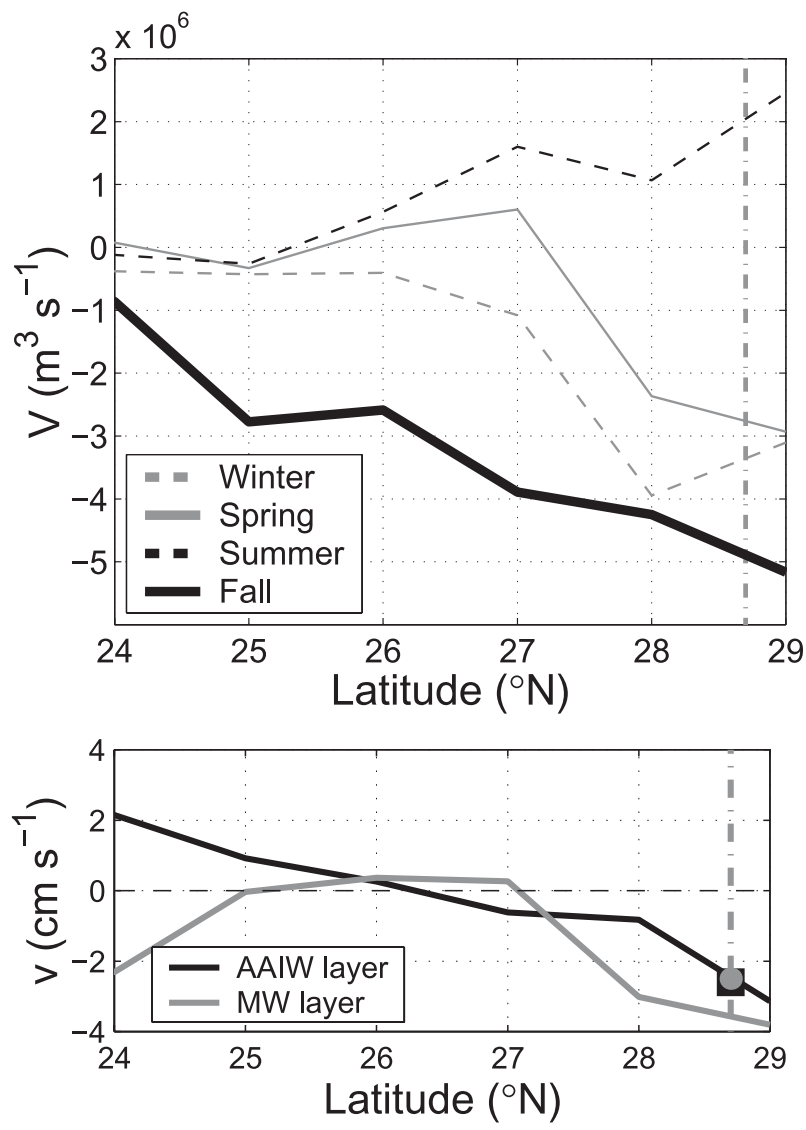

FIG. 6. (top) Latitudinal distribution of volume transport $\left(\mathrm{m}^{3} \mathrm{~s}^{-1}\right)$ calculated with the Sverdrup-type model for different seasons. (bottom) Velocity at intermediate levels as evaluated by the model during fall. The vertical gray line indicates the mooring line location. The black square and gray circle represent the mean November-December velocities at 870 and $1230 \mathrm{~m}$, respectively.

\section{Discussion and conclusions}

The results obtained with this simple model fairly reproduce the intermediate-current inversion patterns observed with the EBC-4 velocity data. The goodness of these results suggests that the vorticity balance of the whole intermediate water stratum (AAIW and MW) is Sverdrupian. South of the Canary Islands, this water stratum is mainly composed of AAIW, whereas north of Cape Ghir $\left(31^{\circ} \mathrm{N}\right)$ it mostly displays MW, with substantial interleaving in between, but the results do suggest that the whole stratum moves meridionally following seasonal stretching or shrinking.

Machín and Pelegrí (2009) proposed that the AAIW motion begins in the tropics through local stretching. Here, we have shown that its motion follows beyond the Canary Islands through the combination of local and advective stretching and in turn influences the MW stratum. In summer (July-September) and early fall (October) the northward AAIW progression reaches beyond the
Canary Archipelago, but most of it returns south every late fall (November-December) accompanied by some MW. This oscillating pattern may be an effective mechanism for the spreading of MW in the eastern boundary of the North Atlantic subtropical gyre.

Acknowledgments. We thank two anonymous reviewers for helpful comments and editor Lynne Talley for her generous and valuable suggestions to improve the manuscript. This study has been performed as part of projects CANOA (CTM2005-00444/MAR) and ORCA (CTM2005-04701-C02-01), funded by Spanish Ministry of Science, and by project RAPROCAN, funded by Instituto Español de Oceanografía. FM was supported by the Juan de la Cierva Programme and by the Postdoctoral Programme of the Universidad de Las Palmas de Gran Canaria.

\section{REFERENCES}

Arhan, M., A. Colin de Vèrdiere, and L. Mémery, 1994: The eastern boundary of the subtropical North Atlantic. J. Phys. Oceanogr., 24, 1295-1316.

Castro, C., F. Pérez, S. Holley, and A. Ríos, 1998: Chemical characterization and modelling of water masses in the northeast Atlantic. Prog. Oceanogr., 41, 249-279.

Fratantoni, D., and P. Richardson, 1999: SOFAR float observations of an intermediate-depth Eastern Boundary Current and mesoscale variability in the eastern tropical Atlantic Ocean. J. Phys. Oceanogr., 29, 1265-1278.

Hernández-Guerra, A., E. Fraile-Nuez, R. Borges, F. LópezLaatzen, P. Vélez-Belchí, G. Parrila, and T. J. Müller, 2003: Transport variability in the Lanzarote Passage (eastern boundary current of the North Atlantic subtropical gyre). Deep-Sea Res. I, 50, 189-200.

— _ , F. López-Laatzen, A. Martínez, G. Parrilla, and P. Vélez-Belchí, 2005: Canary Current and North Equatorial Current form an inverse box model. J. Geophys. Res., 110, C12019, doi:10.1029/2005JC003032.

Iorga, M., and M. S. Lozier, 1999: Signatures of the Mediterranean outflow from a North Atlantic climatology. 2. Diagnostic velocity fields. J. Geophys. Res., 104 (C11), 26 011-26 029.

Jackett, D., and T. McDougall, 1997: A neutral density variable for the world's oceans. J. Phys. Oceanogr., 27, 237-263.

Knoll, M., A. Hernández-Guerra, B. Lenz, F. López-Laatzen, F. Machín, T. J. Müller, and G. Siedler, 2002: The eastern boundary current system between the Canary Islands and the African coast. Deep-Sea Res. II, 49, 3427-3440.

Machín, F., and J. L. Pelegrí, 2009: Northward penetration of Antarctic Intermediate Water off northwest Africa. J. Phys. Oceanogr., 39, 512-535.

— A. Hernández-Guerra, and J. L. Pelegrí, 2006: Mass fluxes in the Canary Basin. Prog. Oceanogr., 70 (2-4), 416-447.

Mittelstaedt, E., 1981: The coastal circulation off Mauritania. Dtsch. Hydrogr. Z., 34 (3), 81-118.

Parrilla, G., S. Neuer, P.-Y. Le Traon, and E. Fernández-Suárez, 2002: Topical studies in oceanography: Canary Islands Azores Gibraltar Observations (CANIGO). Volume 1: Studies in the 
northern Canary Islands basin. Deep-Sea Res. II, 49, 34093413, doi:10.1016/S0967-0645(02)00104-2.

Pérez, F. F., and Coauthors, 2001: Mixing analisys of nutrients, oxygen and inorganic carbon in the Canary Islands region. J. Mar. Syst., 28, 183-201.

Roemmich, D., and C. Wunsch, 1985: Two transatlantic sections: Meridional circulation and heat flux in the subtropical North Atlantic Ocean. Deep-Sea Res., 32, 619-664.

Saenko, O. A., A. J. Weaver, and J. M. Gregory, 2003: On the link between the two modes of the ocean thermohaline circulation and the formation of global-scale water masses. J. Climate, 16, 2797-2801.
Schmid, C., G. Siedler, and W. Zenk, 2000: Dynamics of intermediate water circulation in the subtropical South Atlantic. J. Phys. Oceanogr., 30, 3191-3211.

Siedler, G., L. Armi, and T. J. Müller, 2005: Meddies and decadal changes at the Azores Front from 1980 to 2000. Deep-Sea Res. II, 52 (3-4), 583-604.

Sloyan, B. M., and S. R. Rintoul, 2001: Circulation, renewal, and modification of Antarctic Mode and Intermediate Water. J. Phys. Oceanogr., 31, 1005-1030.

van Aken, H., 2000: The hydrography of the mid-latitude northeast Atlantic Ocean II: The intermediate water masses. Deep-Sea Res. I, 47, 789-824. 